\title{
Waterproofing of bottle gourd (Lagenaria siceraria) with castor oil polyurethane resin
}

\author{
Danieli Maehler Nejeliski ${ }^{1}$, Lauren da Cunha Duarte ${ }^{1}$
}

\author{
${ }^{1}$ Laboratório de Seleção de Materiais - LdSM, PGDesign, Universidade Federal do Rio Grande do Sul - UFRGS, Av. \\ Osvaldo Aranha, 99, sala 604, Porto Alegre, RS, Brasil. \\ e-mail: danielinejeliski@gmail.com, lauren.duarte@ufrgs.br
}

\begin{abstract}
Castor oil is widely used in chemical industry as raw material for paints, coatings, lubricants and a wide variety of other products. It is an important alternative to petrochemical feedstocks for the synthesis of polyurethanes (PU), besides being cost competitive and environmentally friendly alternative. It is used as a substitute for formaldehyde adhesives to produce composites and particleboards. Higher percentages of the resin tend to cause low water absorption and dimensional changes in the panels, so it has potential to use as waterproofing of natural materials. Bottle gourd is a fruit, used worldwide by different peoples as a raw material for the production of artifacts since many thousands of years. After the drying period, the inner part of the shell acquires characteristics similar to wood and the outer shell becomes impermeable. The objective of the work is increasing the durability and extend the useful life of the bottle gourd for use in the product design by waterproofing the material with polyurethane resin derived from castor oil. Untreated samples were compared with one and two layer resin samples. For the water absorption test, reference was made to standard NBR 15316: Medium density fiberboard. The analysis of the results was made through Scanning Electron Microscopy (SEM), water absorption test and contact angle. As a result, the application of the PU resin of castor oil reduced the water absorption indexes, and the samples with two layers of resin obtained the best results.
\end{abstract}

Keywords: lagenaria siceraria, waterproofing, castor oil polyurethane resin.

\section{INTRODUCTION}

The castor oil is obtained from extracting the seed of the plant Ricinus communis. Being a non-edible oil, its use can free up some edible oils used in industry for human consumption. India is the world's largest exporter of castor oil, other major producers are China and Brazil. It is more versatile than other vegetable oils as it is widely used as a starting material for many industrial chemical products because of its unique structure. It is a raw material for paints, coatings, inks, lubricants and a wide variety of other products [1].

Vegetable oil-based polyols are becoming important as alternatives to petrochemical feedstocks for the synthesis of polyurethanes (PU) since they are cost competitive and offer environmentally friendly alternatives. Castor oil is the only commercially available oil polyol that is produced from renewable sources. Using castor oil thus allows synthesizing a variety of PU products, ranging from coatings, thermoplastic elastomers, rigid foams, semi-rigid foams, flexible foams, sealants and adhesives [2].

The use of polyurethane resin derived from castor oil is as a substitute for formaldehyde adhesives in the production of composites and particleboards. Fiorelli et al [3] developed panels of sugarcane bagasse with polyurethane resin based on castor oil. Marinho et al [4] and De Almeida et al [5] developed particleboards from bamboo waste. Silva et al [6] developed multilayer particleboard panels, which core was produced with sugarcane bagasse and as facing materials Pinus taeda particles and Malva fibres. A spray-up process was used to spread castor oil based polyurethane resin upon the dispersive phases. Nogueira et al [7] used waste from Brazil's nut in the manufacture of particleboards using castor oil polyurethane adhesive.

As a result, all treatments reached the minimum strength except for elastic modulus. Higher percentages of the resin tend to cause low water absorption and dimensional changes in the panels, as well as higher strength values. Calegari et al [8] analyzed the waterproofing Medium Density Fiberboards (MDF) with different coatings such as polyurethane resin 
on castor oil-based, acrylic lacquer and marine varnish. The samples with polyurethane resin to castor oil-based coating presented the best results, that is, lower levels of water absorption and lower thickness swelling and volume.

The use of natural materials from renewable sources is an alternative to non-renewable resources that are doomed to extinction. However, the feasibility of applying organic materials in the manufacture of products depends on the application of treatments that can increase the durability and extend the useful life of the material. Bottle gourd (Lagenaria siceraria) is used worldwide by different peoples as a raw material for the production of artifacts since many thousands of years. The scientific name of bottle gourd refers to "drinking vessel" which is a main use of the fruit. In Africa, in addition to production of food and beverage containers, gourd has been exploited for thousands of years in the making of musical instruments because of its excellent acoustic properties. It is used as a resonance chamber of stringed instruments in India [9]. Bottle gourd used as container for transport and storage of liquids persists until this day [10]. Renewable source material, biodegradable, with annual productive cycle and high productivity, gourd is an alternative of eco-friendly material.

Evidence of the use of the fruit was found in different continents and several civilizations. Objects made of gourd dating back to 11,000 BC were found in East Asia. In the American continent, the fruits were used since 10,000 BC [11]. In South America, records date at 6,000 to 5,000 BC [12]. Among the domesticated animals and plants, only the dog has spread more widely on the globe than gourd [11]. The fruit belongs to the family of Cucurbitaceae, cultivation adapted to tropical climate, planting is annual at the end of winter. About 150 days after planting, the natural drying of the fruits takes place and the harvest is done manually. After harvest, the fruit is placed in shade for slow drying, a process that can take a few months [13]. After drying, the placenta with the seeds dries and the fruit becomes hollow. The inner part of the shell acquires similar characteristics like wood and the outer shell, extremely thin and smooth, becomes impermeable.

Organic materials change rapidly when in contact with physical, chemical and biological factors that naturally activate and interfere with the decomposition process. The function of the waterproofing treatments is to delay the effects caused by the external agents, increasing the useful life of the material. Wood is an organic material whose preservation research is very advanced. Research on less aggressive waterproofing agents has been gaining prominence, such as vegetable oils and waxes. Castor oil polyurethane resin is an ecofriendly alternative because the raw material is from a renewable source. The objectives of this research are increasing the durability and extend the useful life of the bottle gourd for use in the product design by waterproofing the material with polyurethane resin derived from castor oil.

\section{MATERIALS AND METHODS}

The morphological variation of bottle gourd is a characteristic feature of the species (Figure 1a), there are many variations of shape, size and thickness [14]. The fruits used in this work were collected in Santa Maria, Rio Grande do Sul state, Southern Brazil. They were purchased from Fábrica de Cuias Fracari ${ }^{1}$. The samples were made from four different fruits (Figure 1b). Fruits samples with similar shapes were selected to obtain samples with similar dimensions.
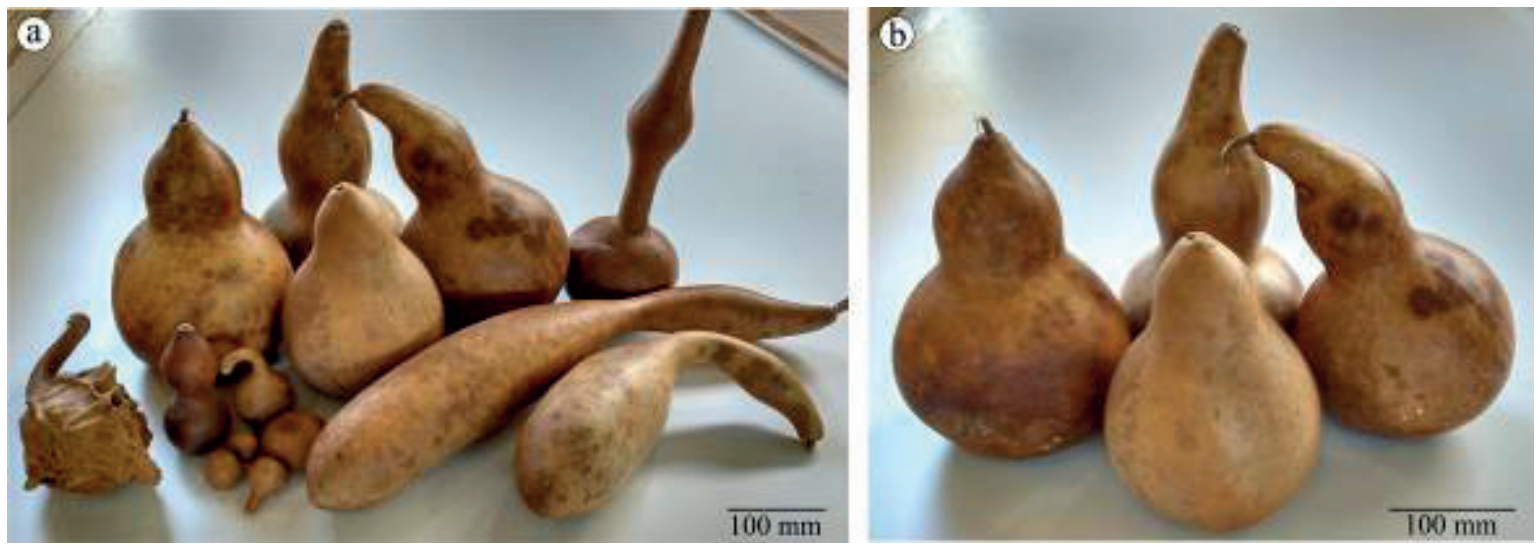

Figure 1: Bottle gourd: a) morphological variation of the species; b) fruits selected.

${ }^{1}$ http://cuiasfracari.com.br/ 


\subsection{Sample preparation}

The sample preparation was adapted from standard NBR 7190: Design of wooden structures [15], since no specific standard was found for the material or for materials with heterogeneous forms. The standard establishes that the samples should have a rectangular cross section measuring $50 \times 30 \mathrm{~mm}$ and $20 \mathrm{~mm}$ thick. Due to bottle gourd's concave shapes and irregular shell thickness, the measurements were adapted to $50 \mathrm{~mm}$ in the transverse of the fruit, $30 \mathrm{~mm}$ in the longitudinal direction and $5 \mathrm{~mm}$ in thickness.

For the preparation of the samples, the fruits were cut in the middle in the longitudinal direction (Figure 2a) with a bench saw. With the fruit open, we can observe its constitution. After the drying process of bottle gourd, the smooth endocarp ( 1 in Fig. 2a) envelops and sticks to the seeds ( 2 in Fig. 2a). Mesocarp becomes a rigid, porous, light-colored layer and covers almost the entire material ( 3 in Fig. 2a). Exocarp has darker color, is composed of a micrometer-thick, smooth and homogeneous layer (4 in Fig. 2a). For the cut of the samples, the seeds of the fruits were removed. The rectangular samples were cut in the miter saw (Figure 2b). Finally, the mesocarp portion of the samples (internal part, lighter in color) was sanded to homogenize the surface for resin application. In total, 36 samples with approximate dimensions of $30 \mathrm{~mm}$ of width by $50 \mathrm{~mm}$ of length and $5 \mathrm{~mm}$ of thickness were obtained.
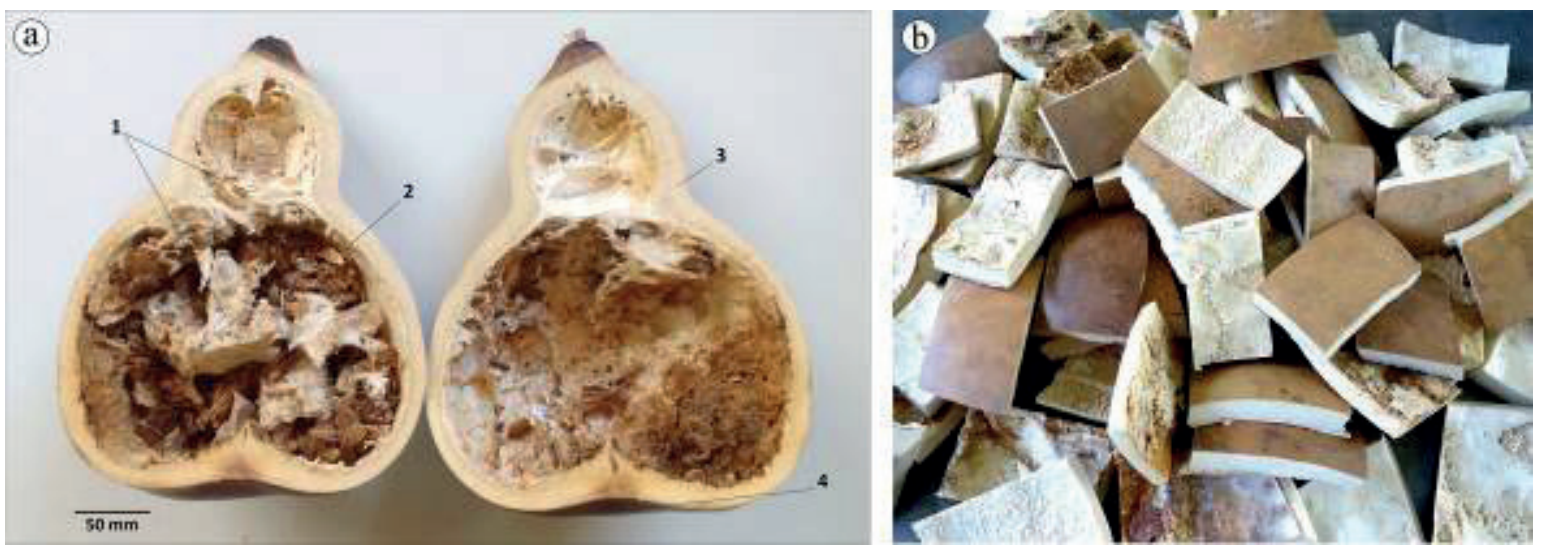

Figure 2: Samples of bottle gourd: a) fruit after the drying process in longitudinal section: (1) endocarp, (2) seeds, (3) mesocarp, (4) exocarp.; b) samples with approximate dimensions of $30 \mathrm{~mm}$ of width by $50 \mathrm{~mm}$.

Polyurethane resins based on castor oil from two different companies, Imperveg® RM 122 [16] and e Sinergia ${ }^{\circledR}$ sort V, for wood and similars [17], respectively A and B. Both have very similar characteristics. They are bicomponent resins, (I + II), the first being castor oil and the second the catalyst. One part of component I + two parts of component II, by volume, must be admixed in the ratio of $1: 2$ for the polymerization to commence. The mixture is viscous; the working time is about 20 minutes, when the resin enters into the gel point, making it difficult to apply the material.

The samples were divided in three groups (Figure 3). The first one consists of six pieces in natura, without any type of treatment; the second is composed of twelve samples with application of resin A; and the third group for another twelve pieces with application of resin B, totaling the 30 samples. In each group of resin samples, six were given the application of one coat of the product and the other six, two coats of the resin. 


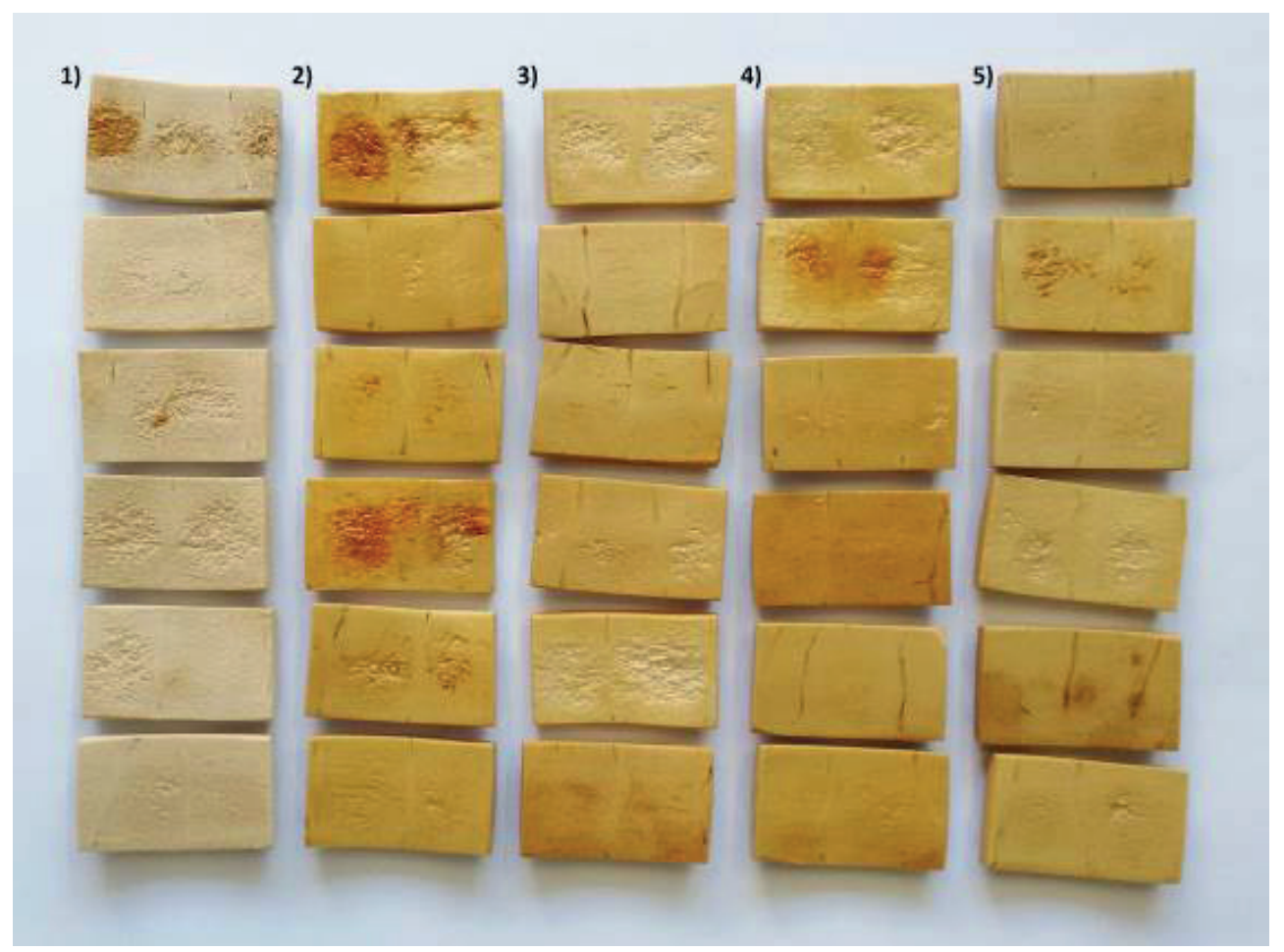

Figure 3: Set of samples with the variables selected for this study, which are: 1) Bottle gourd in natura; 2) Samples with application of resin A with one coat e; 3) with two coats; 4) Samples with application of resin B, with one coat e; 5) with two coats.

The drying time ranged from 40 to 180 minutes, depending on the temperature and humidity of the environment. The maximum time between the application of subsequent coats was approximately six hours, during which time the total polymerization occurs. The color of the resins after the cure is amber, due to the castor oil that has a dark coloration. The material is solvent free and forms a membrane on the surface on which it was applied. It is a system molded in loco and adherent to the substrate. The resins were applied in the mesocarp of the bottle gourd (permeable portion) and the application was done by brushing. Water absorption tests were performed two days after resin application to the samples.

\subsection{Methods of analysis}

For the analysis of the results through Scanning Electron Microscopy (SEM) the equipment used is the brand Hitachi ${ }^{\circledR}$, model TM 3000, located in the premises of Laboratório de Design e Seleção de Materiais - LdSM, in Universidade Federal do Rio Grande do Sul - UFRGS. The acceleration of the electron beam used was $15 \mathrm{KeV}$, and the equipment operates with image magnification up to 30,000 times. BSE (backscattered electron) electron images were obtained.

For the water absorption test, reference was made to standard NBR 15316: Medium density fiberboard [18], since there is no specific standard for bottle gourd. The water absorption test consists in measuring the increase in the mass (in water) that a test piece of the material presents, after being immersed in water at $20 \pm 1^{\circ} \mathrm{C}$ for a time of $24 \mathrm{~h} \pm 36 \mathrm{~min}$. The specimens shall be weighed on a precision scale and then packed in a vessel containing water at room temperature. Two measurements were taken, one after two hours of immersion, and another after 24 hours. The mass of the samples were recorded for the water absorption definition, calculated by the following equation:

$$
A \%=\frac{M_{2}-M_{1}}{M_{1}} .100
$$

$A \%$ is the absorption of water, in percentage.

$M_{1}$ is the initial mass of the test specimen in grams.

$M_{2}$ is the final mass of the test specimen after test in grams.

The contact angle $(\theta)$ between a solid surface, a liquid phase and a gaseous phase is defined as the angle between the 
solid-liquid interface and the tangent to the liquid-gas interface in the contact point of these three phases. From this information a solid material can be classified as hydrophilic or hydrophobic [19]. There are several methods for determining the contact angle. The scattering method is the process in which a drop of liquid is deposited on the flat surface of a horizontally positioned solid. The liquid forms a spherical surface, spreading over the surface of the solid to reach the equilibrium contact angle, in which the solid /liquid adhesion forces are in equilibrium [20]. The tests to determine the contact angle were performed in three bottle gourd samples range: natural, with one and two layers of resin. The images were obtained with a digital camera in Laboratório de Materiais Cerâmicos - LACER of UFRGS.

\section{RESULTS AND DISCUSSION}

The possibility of applying the resin without methods such as vacuum or use of specific equipment is a positive point, because it facilitates the process of waterproofing the materials in a non-industrial scenario. The resins were applied with the aid of brushes. Because they are solvent-free, both are difficult to dilute, with manufacturers recommending the use of $96 \%$ alcohol to clean brushes and containers. However, the method was not effective, so that after curing the resins, the material had to be discarded, with no possibility of reuse. This is a negative aspect of brushing, making it necessary to search for more effective means of application.

Regarding the aesthetic aspect of the material, after the application and curing of the resins, the samples had a slightly darker shade (Figure 4), an amber tone, as described in the product information. This is due to castor oil, which has a dark coloration. Samples that received one layer of the resins presented uniform matte finish, excellent absorption, without deposition of the material in the recesses (Figure 4-2 and 4-4). The samples that received two layers did not obtain a very satisfactory final finish. The second polymer layer overlapped the first, in many regions of the samples there was accumulation of the resin. The samples presented a finish with heterogeneous brightness, with areas more protruding than other (Figure 4-3 and 4-6). Thus, the resin altered the natural color of the bottle gourd, but not to the point of de-characterizing the material.

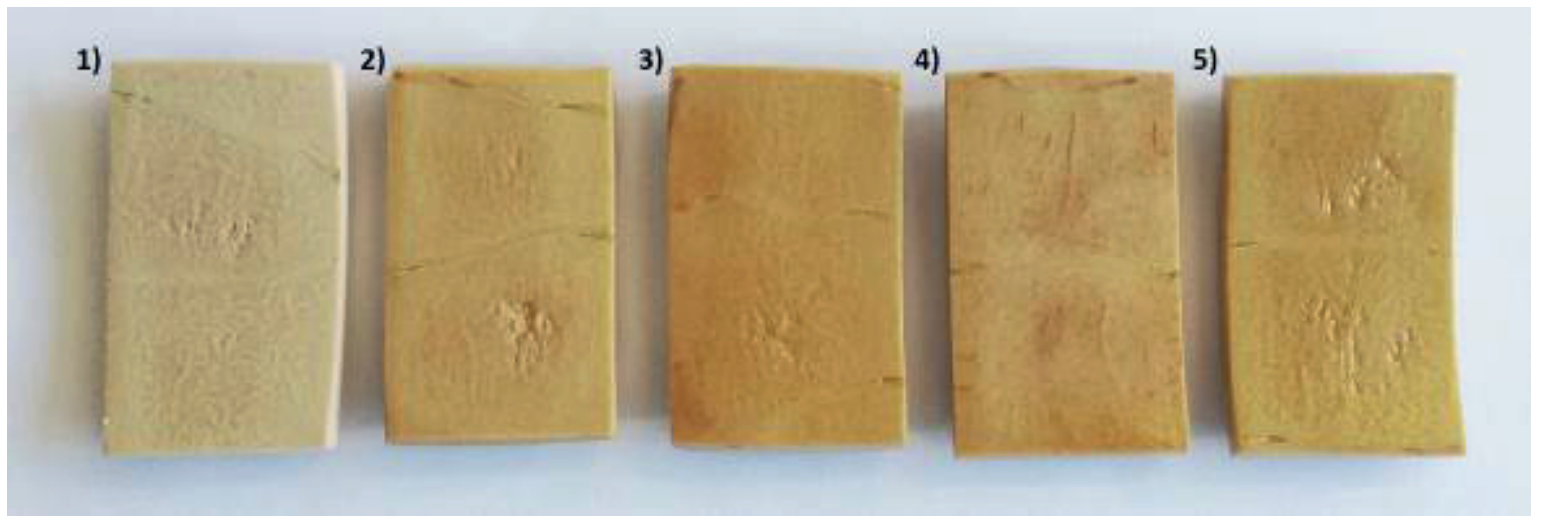

Figure 4: Samples of bottle gourd without treatment and after application of resins: 1) Sample without treatment; 2) With a layer of resin A; 3) With two layers of resin A; 4) With a layer of resin B; 5) With two layers of Resin B.

The difference between untreated samples with one resin layer and two layers is more visible in the images seen in the scanning electron microscope (Figure 5). Figures 5a and 5b show the untreated bottle gourd, respectively, the exocarp and mesocarp. The exocarp shows a micrometric and impermeable layer (Fig. 5a), with a compact structure and bright punctuations, identified as inorganic materials. The mesocarp is a network of pores, of varying sizes and shapes and distinct stretching directions (Figure 5b), which defines it as a less compact and less dense structure than the exocarp. Figures 5c and $5 \mathrm{~d}$ show the mesocarp of bottle gourd after the waterproofing, respectively, with a layer of resin and two layers. In the one layer resin bottle gourd material (Figure 5c) the resin was well absorbed by the samples, because it is still possible to observe elements of the surface of the material, indicating that the surface layer of the resin became very thin and adhered to the material. In the samples that received two layers of resin (Figure 5d) can be observed that, the last one overlapped with the existing one, forming a polymeric film, which in the image of the microscope appears as a regular layer, where no more can be visualized aspects of the mesocarp. 

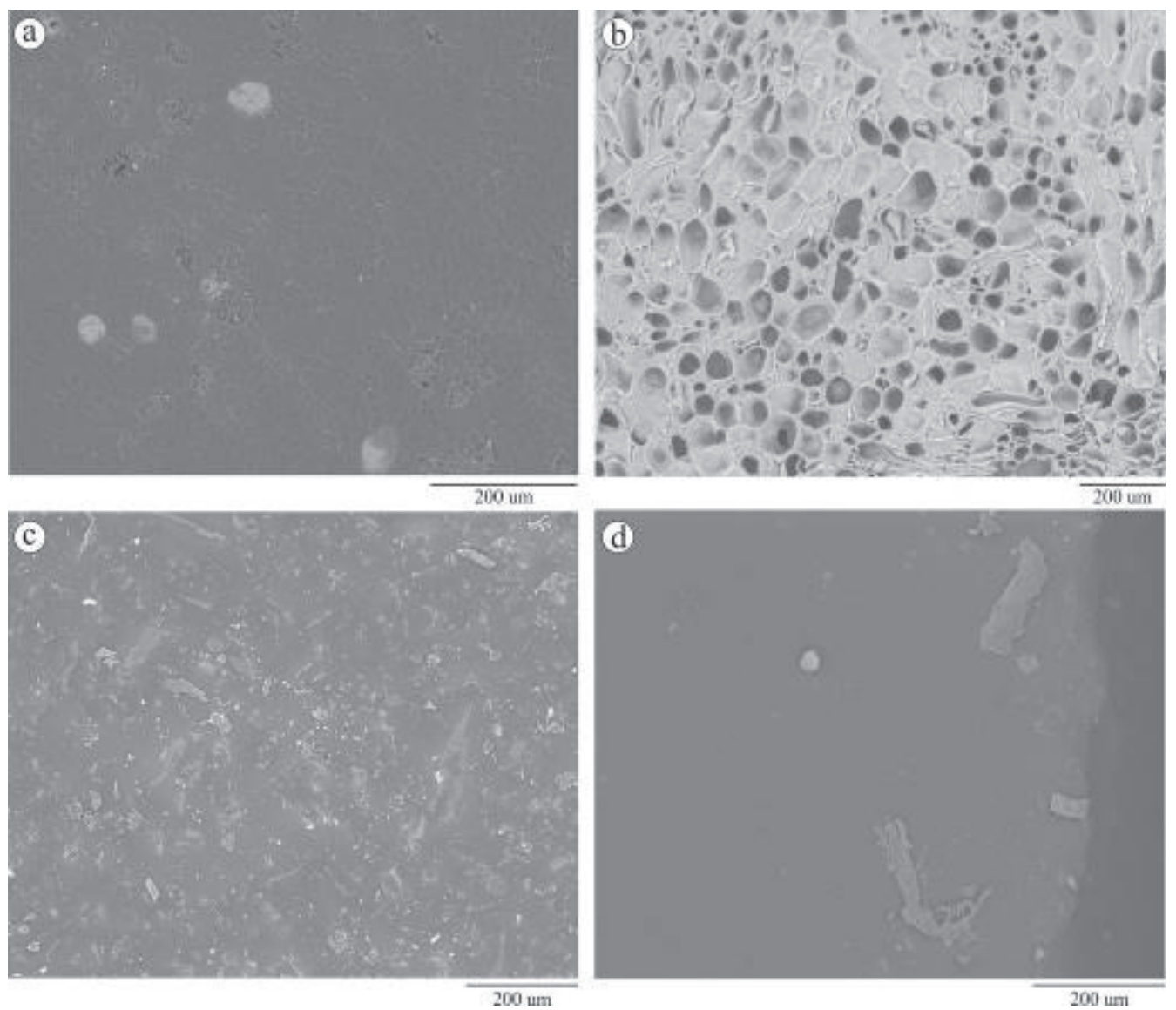

Figure 5: Untreated samples and resin samples: a) Exocarpo, compact and homogeneous layer, with clear points of inorganic materials; b) Mesocarp, porous structure formed by the cells of the parenchyma; c) Sample with a layer of resin A; d) Sample with two layers of resin A.

The objective of the water absorption analysis is generate a comparison between the indices of the natural samples and the potential waterproofed samples, and also between them, with one and two layers of resin, in order to analyze the efficiency of the waterproofing method. Table 1 shows the water absorption results, in grams, of the untreated bottle gourd samples. Tables 2 and 3 show the results of the samples with resin A, with one and two layers, respectively. Tables 4 and 5 show the results of the samples with resin B, with one and two layers.

Table 1: Water absorption measurements of untreated samples.

\begin{tabular}{c|c|c|c|c}
\hline Samples & Number & Absorption 0 hs & Absorption 2 hs & Absorption 24 hs \\
\hline \multirow{5}{*}{ Untreated } & 1 & 1.371 & 3.416 & 3.459 \\
\cline { 2 - 5 } & 2 & 2.531 & 3.665 & 3.933 \\
\cline { 2 - 5 } & 3 & 1.528 & 3.340 & 3.773 \\
\cline { 2 - 5 } & 4 & 1.652 & 3.072 & 3.195 \\
\cline { 2 - 5 } & 5 & 1.380 & 2.857 & 3.036 \\
\hline \multicolumn{2}{c}{ Average } & 1.586 & 2.843 & 3.422 \\
\hline
\end{tabular}


Table 2: Samples measurements with one layer of resin A.

\begin{tabular}{c|c|c|c|c}
\hline Samples & Number & Absorption 0 hs & Absorption 2 hs & Absorption 24 hs \\
\hline \multirow{4}{*}{$\begin{array}{c}\text { Resin A } \\
\text { One layer }\end{array}$} & 1 & 1.706 & 1.903 & 3.464 \\
\cline { 2 - 5 } & 2 & 1.862 & 2.086 & 2.890 \\
\cline { 2 - 5 } & 3 & 2.777 & 2.990 & 3.242 \\
\cline { 2 - 5 } & 4 & 2.561 & 2.770 & 2.976 \\
\cline { 2 - 5 } & 6 & 2.872 & 3.108 & 3.390 \\
\hline \multicolumn{2}{c}{ Average } & 1.742 & 1.976 & 2.605 \\
\hline \multicolumn{2}{c}{} & 2.253 & 2.472 & 3.094 \\
\hline
\end{tabular}

Table 3: Samples measurements with two layers of resin A.

\begin{tabular}{c|c|c|c|c}
\hline Samples & Number & Absorption 0 hs & Absorption 2 hs & Absorption 24 hs \\
\hline \multirow{4}{*}{$\begin{array}{c}\text { Resin A } \\
\text { Two layers }\end{array}$} & 1 & 2.668 & 2.720 & 2.870 \\
\cline { 2 - 5 } & 2 & 2.788 & 2.833 & 2.955 \\
\cline { 2 - 5 } & 3 & 1.927 & 1.997 & 2.097 \\
\cline { 2 - 5 } & 4 & 2.743 & 2.762 & 2.856 \\
\cline { 2 - 5 } & 5 & 3.033 & 3.089 & 3.226 \\
\hline \multicolumn{2}{c}{ Average } & 1.712 & 1.759 & 1.836 \\
\hline
\end{tabular}

Table 4: Samples measurements with one layer of resin B.

\begin{tabular}{|c|c|c|c|c|}
\hline Samples & Number & Absorption 0 hs & Absorption 2 hs & Absorption 24 hs \\
\hline \multirow{6}{*}{$\begin{array}{l}\text { Resin B } \\
\text { One layer }\end{array}$} & 1 & 2.539 & 2.749 & 2.984 \\
\hline & 2 & 2.044 & 2.234 & 2.366 \\
\hline & 3 & 1.616 & 1.826 & 2.532 \\
\hline & 4 & 2.766 & 3.004 & 3.301 \\
\hline & 5 & 2.644 & 2.812 & 3.306 \\
\hline & 6 & 2.518 & 2.762 & 2.968 \\
\hline \multicolumn{2}{|c|}{ Average } & 2.354 & 2.564 & 2.909 \\
\hline
\end{tabular}

Table 5: Samples measurements with two layers of resin B.

\begin{tabular}{c|c|c|c|c}
\hline Samples & Number & Absorption 0 hs & Absorption 2 hs & Absorption 24 hs \\
\hline \multirow{4}{*}{$\begin{array}{c}\text { Resin B } \\
\text { Two layers }\end{array}$} & 1 & 3.026 & 3.086 & 3.179 \\
\cline { 2 - 5 } & 2 & 2.548 & 2.597 & 2.652 \\
\cline { 2 - 5 } & 3 & 2.932 & 2.988 & 3.073 \\
\cline { 2 - 5 } & 4 & 2.757 & 2.841 & 2.923 \\
\cline { 2 - 5 } & 5 & 1.686 & 1.739 & 1.775 \\
\hline \multicolumn{2}{c}{ Average } & 1.759 & 1.806 & 1.829 \\
\hline
\end{tabular}

Graph 1 shows the water absorption relation between mass (g) and time (h), where it starts from the initial mass of the samples. The curve of mass gain for the natural bottle gourd is clearly more pronounced than the others. Regarding the resins, the two brands showed very similar performance. It can be observed that the samples with a waterproofing layer had a slightly higher mass gain than those with two layers and that the latter had a minimum mass gain. To better visualize this data, Graph 2 brings the data of water absorption from the increase of mass in percentage. 


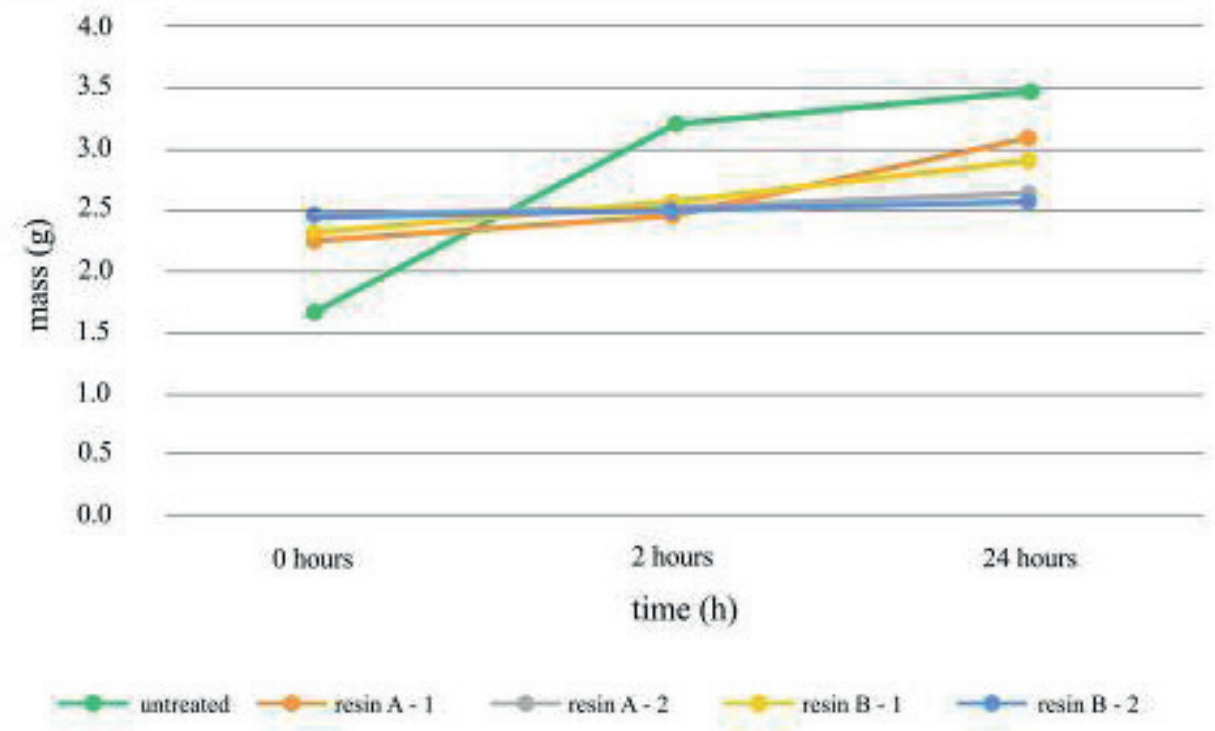

Graph 1: Absorption of water in increasing mass (g) x time (h): Untreated samples; Resin A-1: Samples with one layer of resin A; Resin A-2: Samples with two layers of resin A; Resin B-1: Samples with one layer of resin B; Resin B-2: Two-layer samples of resin B.

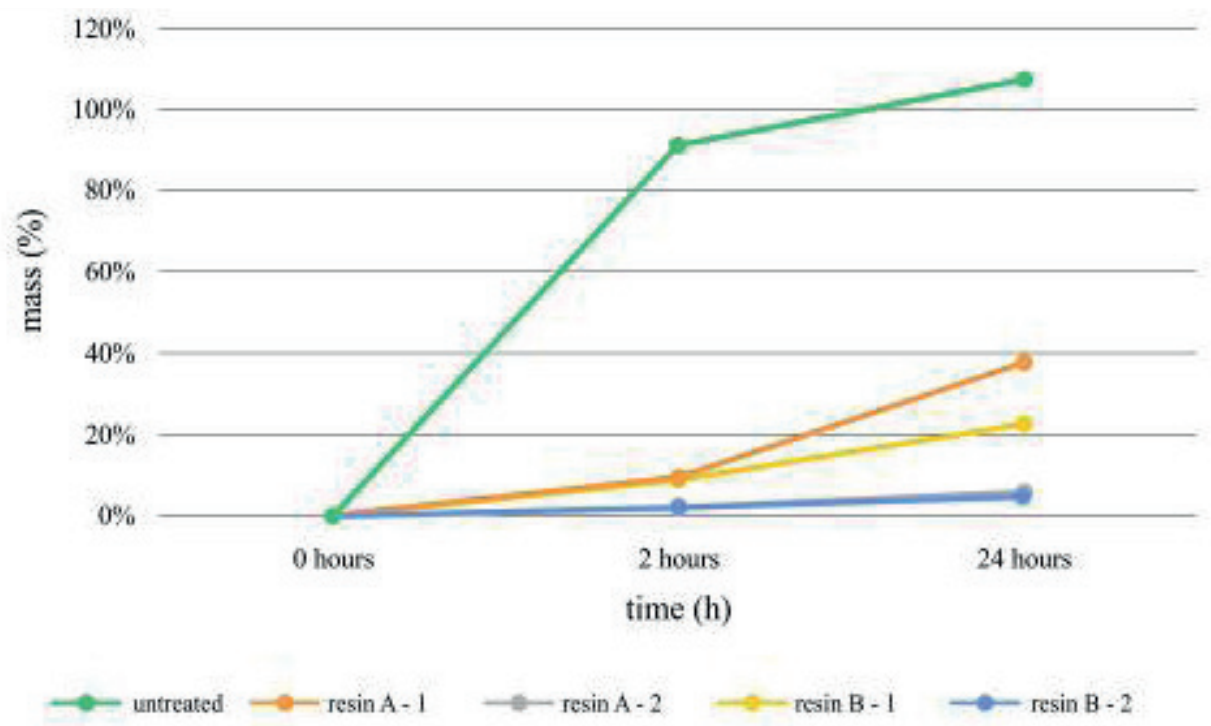

Graph 2: Absorption of water in increasing mass (\%) x time (h): Untreated samples; Resin A-1: Samples with one layer of resin A; Resin A-2: Samples with two layers of resin A; Resin B-1: Samples with one layer of resin B; Resin B-2: Two-layer samples of resin B.

When comparing the percentage of mass increase of the samples, there is a greater disparity between the results. The water absorption of the unwaterproofed sample is very high, in this case reaching a mass increase of $107 \%$ with respect to the initial measurement. Samples with a resin layer of the A and B marks after 2 hours in water had a $9 \%$ mass increase, and after 24 hours, a $37 \%$ and $23 \%$ increase, respectively. The samples with two layers of resin were the ones that presented the lowest indices of water absorption, with very similar results. After 2 hours, gain just $2 \%$ of mass and after 24 hours, just $6 \%$ and $5 \%$, respectively.

In order to corroborate the waterproofing results obtained with the polyurethane resin based on castor oil, the re- 
sults of the absorption test were compared with those achieved by Lago [21], from the polymer impregnation of the bottle gourd with solutions of methylmethacrylate - MMA and methanol-MeOH, in proportions of 70/30, 80/20 and 90/10, and different impregnation methods. In the simple immersion impregnation method, without vacuum, after 24 hours in water, the samples had a considerable mass increase, between 45 and $60 \%$. In the 30 min vacuum method +30 min immersion, after 24 hours, the samples obtained a mass gain between 30 and $45 \%$. Finally, the 30 min vacuum method +24 hours of immersion was the one that obtained the most satisfactory results, where after 24 hours of immersion there was a mass gain between 20 and $35 \%$.

Based on the most satisfactory results achieved by Lago [21], the polymeric impregnation method, in which the samples with the lowest water absorption index were between 20 and 35\%, it can be said that the samples with a layer of polyurethane oil resin yielded very similar results, varying from 23 to $37 \%$, with similar efficiency. The results of the samples with two layers of resin left the bottle gourd practically impermeable, with 5 and $6 \%$ of mass gain after 24 hours in the water. In general, the results of waterproofing with resins can be considered satisfactory, since there was a reduction in the indices of water absorption, with either one or two layers of the substance. But is reasonable show, that the aesthetic aspect of the samples impregnated by polyurethane oil resin is unmodified when compared to natural samples of bottle gourd.

Complementing the water absorption tests, the contact angle test is used to classify the material, waterproofed or not, as hydrophilic or hydrophobic. Among the different methods for the definition of the contact angle, the method of wetting by scattering was chosen. Untreated samples were compared with one and two resin layers. In the method of wetting by spreading, low contact angles indicate that the spreading was not accentuated [20]. When the test is conducted with water it is possible to classify the solid as hydrophilic at contact angles of less than $90^{\circ}$ or hydrophobic at contact angles greater than $90^{\circ}$. Figure 6 shows the images resulting from wetting by water spreading in bottle gourd samples.
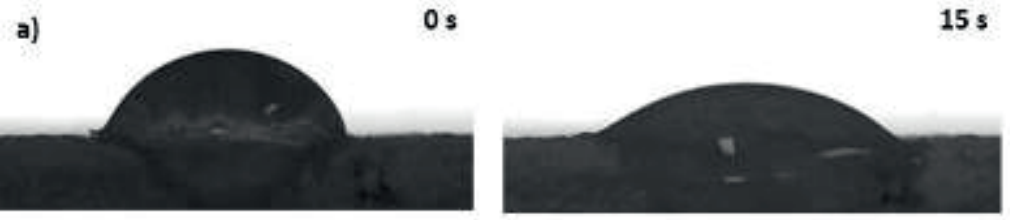

15 s

b)

os

$15 \mathrm{~s}$
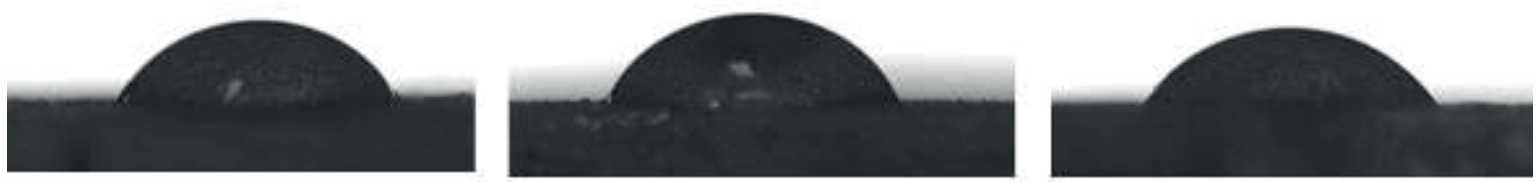

c)

os

15 s

$30 \mathrm{~s}$
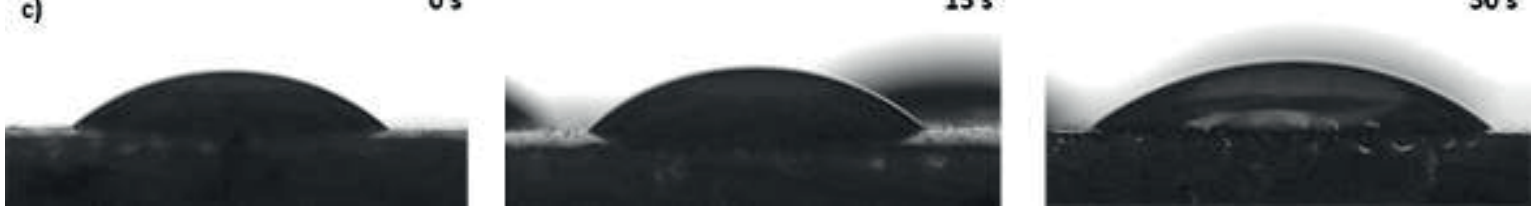

Figure 6: Drop angle test by scattering method: a) Natural pore sample; b) Sample with a layer of resin A; c) Sample with two layers of resin $\mathrm{A}$. The numbering $0 \mathrm{~s}, 15 \mathrm{~s}$ and $30 \mathrm{~s}$, in the upper right corner of each figure, indicates the time in seconds.

The results of the contact angle of the natural porous mesocarp sample (Fig. 6a) confirm the high permeability of the material, which can be defined as highly hydrophilic, since the water was totally absorbed by the sample. The results of the one and two layer resin samples (Fig. 6b and 6c) were similar. In Figure 7 we can observe the demarcation of the contact angle formed in the samples with one resin layer and two layers. 
a)

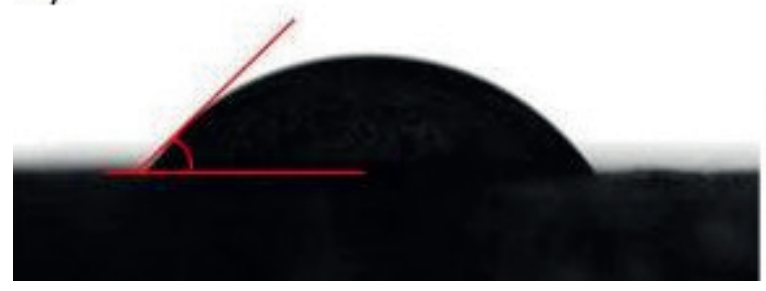

b)

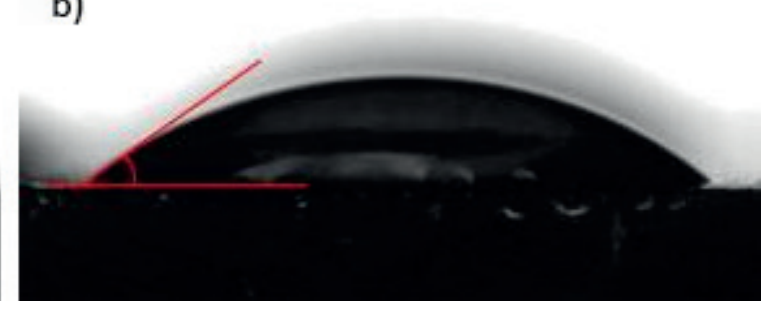

Figure 7: Indication of contact angle less than $90^{\circ}$ in the resin samples: a) Samples with a resin layer; b) Sample with two layers of resin.

It can be observed that, although they do not completely absorb the liquid, the contact angle formed in the two samples is less than $90^{\circ}$, so that after application of the resin the material cannot be considered hydrophobic but has a certain degree of impermeability. This result can be reiterated through the data obtained in the water absorption test of the samples, which indicates that even with the resin layer, bottle gourd continues to absorb a certain amount of water.

From the analysis of the results of the tests of waterproofing of the bottle gourd come two main aspects: the characterization of bottle gourd as a highly hydrophilic material and the polyurethane resin based on castor oil as an efficient waterproofing when applied to the material. The water absorption rates of the waterproofing material have drastically reduced, retarding the degradation of the material and facilitating the cleaning of the material, increasing its durability.

\section{CONCLUSIONS}

Concerning the polyurethane resin based on castor oil, it is one of the alternatives of new polymeric materials where the raw material is a renewable source material. Being a relatively new material in the market, the acquisition was difficult, with only two brands being sampled. By being a material in the research phase, it has some aspects to be improved, as in the case of establishing a substance to remove the residues of the resin after the application, so that the used tools can be reused.

Applied to the bottle gourd, the resin slightly altered the natural aesthetic characteristics of the material, one of the prerequisites, only slightly darkening the inner part. As a waterproofing agent, it has drastically reduced the absorption rates of material. With a layer of resin applied the mass gain was between $23 \%$ and $37 \%$, and with two layers applied, the material was practically impermeable, with mass gain of $5 \%$ and $6 \%$ only. It can be said that the polyurethane resin based on castor oil has proved to be effective and has achieved the objectives in waterproofing the bottle gourd for the product design.

\section{ACKNOWLEDGEMENTS}

This study was supported by Conselho Nacional de Desenvolvimento Científico e Tecnológico (CNPq - Brazil) and the Coordenação de Aperfeiçoamento de Pessoal de Nível Superior (CAPES - Brazil).

\section{BIBLIOGRAPHY}

[1] OGUNNIYI, D.S., “Castor oil: a vital industrial raw material”, Bioresource Technology, v. 97, pp. 1086-1091, 2006.

[2] MUTLU, H., MEIER, M.A.R., "Castor oil as a renewable resource for the chemical industry", European Journal of Lipid Science and Technology, v. 112, pp. 10-30, 2010.

[3] FIORELLI, J., LAHAR, F.A.R, NASCIMENTO, M.F., et al."Painéis de partículas à base de bagaço de cana e resina de mamona: produção e propriedades”, Acta Scientiarum. Technology, v. 33, n. 4, pp. 401-406, 2011.

[4] MARINHO, N.P., NASCIMENTO, E.M., NISGOSKI, S., et al. "Caracterização física e térmica de compósito de poliuretano derivado de óleo de mamona associado com partículas de bambu”, Polímeros: Ciência e Tecnologia, v. 23, n. 2 , pp. 201-205, 2013.

[5] DE ALMEIDA, A.C., DE ARAÚJO, V.A., MORALES, E.A.M., et al."Wood-bamboo particleboard: mechanical properties", Bioresources, v. 12, n. 4, pp. 7784-7792, 2017.

[6] SILVA, M.R., PINHEIRO, R.V., CHRISTOFORO, A.L., et al."Hybrid sandwich particleboard made with sugarcane, Pínus Taeda thermally treated and Malva fibre from Amazon”, Materials Research, v. 21, n. 1, 2018.

[7] NOGUEIRA, I.M. dos S., LAHR, F.A.R., GIACON, V.M. "Desenvolvimento e caracterização de painéis de partículas 
aglomeradas utilizando o resíduo do ouriço da Castanha-do-Brasil (Bertholletia excelsa) e resina poliuretana derivada do óleo da mamona", Revista Matéria, v. 23, n. 1, 2018.

[8] CALEGARI, E.P., PORTO, J.S., NEJELISKI, D.M., et al."Experimental study on waterproofing MDF with castor oilbased vegetal polyurethane", Revista Matéria, v. 22, n. 3, 2017.

[9] BURTENSHAW, M. "The first horticultural plant propagated from seed in New Zealand: Lagenaria sicera-ria", New Zealand Garden Journal, v. 6, n. 1, p 10-16, 2003.

[10] BASTOS, M. A.B. Poética da cabaça: fruto de tradição, arte e comunicação. Dissertação Mestrado em Artes, Universidade Estadual Paulista, São Paulo, Brasil, 2010.

[11] KISTLER, L., MONTENEGRO, A., SMITH, B.D., et al. "Transoceanic drift and the domestication of African bottle gourds in the Americas", Proceedings of the National Academy of Sciences of the United States of America, v. 111, n. 8, 2014.

[12] BISOGNIN, D.A., "Origin and evolution of cultivated cucurbits", Revista Ciência Rural, v. 32, n. 5, p. 715 - 723 , 2002.

[13] BISOGNIN, D.A., SILVA, A.L.L. "A cultura do porongo". Informe técnico, ed. Pelo Departamento de Fitotecnia do centro de Ciências Rurais (CCR) da Universidade Federal de Santa Maria (UFSM), 2004.

[14] SILVA, A.L.L., BISOGNIN, D.A., ZACHIA, R.A., et al.“Coleta e caracterização morfológica de populações de porongo - Lagenaria siceraria (Mol.) Standl. - Cucurbitaceae”, Revista Ciência \& Natura, pp. 91 - 100, 2002.

[15] ABNT, Associação Brasileira de Normas Técnicas, "NBR 7190: Projeto de estruturas de madeira". Rio de Janeiro, 1997.

[16] IMPERVEG. Ficha técnica Imperveg RM 122. Available in: <http://imperveg.com.br/wp-content/uploads/2015/04/ FICHA_TECNICA_IMPERVEG_RM_122.pdf >.Access in 20 jul. 2018.

[17] SINERGIA. Linha de produtos: Tipo "V" madeiras e similares. Available in: $<$ https://sinergiaservice.com.br/produtos. html>. Access in 20 jul. 2018.

[18] ABNT, Associação Brasileira de Normas Técnicas, "NBR 15316: Painéis de fibras de média densidade". Rio de Janeiro, 2014.

[19] WOLF, F.G., DOS SANTOS, L.O.E., PHILIPPI, P.C. "Formação e dinâmica da interface líquido-vapor simulada pelo método Lattice-Boltzmann", Revista Brasileira de Ensino de Física, vol. 28, n. 2, São Paulo, 2006.

[20] LAZGHAB, M., PEZRON, I., SALEH, K., et al."Wettability assesment of finely divided solids”, Powder Tecnology, v. 157, n. 1-3, p. 79-91, 2005.

[21] LAGO, T., Caracterização e impregnação polimérica do porongo (Lagenaria siceraria) visando aplicação no design de biojóias. Dissertação (Mestrado em Design), Universidade Federal do Rio Grande do Sul, Porto Alegre, 2013.

\section{ORCID}

Danieli Maehler Nejeliski

Lauren da Cunha Duarte
https://orcid.org/0000-0002-4487-539X

https://orcid.org/0000-0001-5690-0794 